\title{
The Social Media "Magic": Virtually Engaging Visitors during COVID-19 Temporary Closures
}

\author{
Brittany Ryder, Tingting Zhang *(D) and Nan Hua \\ Rosen College of Hospitality Management, University of Central Florida, Orlando, FL 32819, USA; \\ brittany.ryder@knights.ucf.edu (B.R.); nan.hua@ucf.edu (N.H.) \\ * Correspondence: tingting.zhang@ucf.edu
}

check for

updates

Citation: Ryder, Brittany, Tingting Zhang, and Nan Hua. 2021. The Social Media "Magic": Virtually Engaging Visitors during COVID-19 Temporary Closures. Administrative Sciences 11: 53. https://doi.org/ 10.3390/admsci11020053

Received: 3 March 2021

Accepted: 18 May 2021

Published: 24 May 2021

Publisher's Note: MDPI stays neutral with regard to jurisdictional claims in published maps and institutional affiliations.

Copyright: (c) 2021 by the authors. Licensee MDPI, Basel, Switzerland. This article is an open access article distributed under the terms and conditions of the Creative Commons Attribution (CC BY) license (https:/ / creativecommons.org/licenses/by/ $4.0 /)$.

\begin{abstract}
The purpose of this study was to explore what types of digital content cultural institutions implemented during COVID-19 temporary closures and their effects on social media engagement. Existing research identified the role of digital content and social media in cultural institutions, but only in times of normal operations. This study adds to the existing literature by exploring the types of digital content implemented, impacts on social media engagement, measures of social media engagement, and future implications in regard to COVID-19 temporary closures. This study recruited 66 cultural institutions from across the United States to take part in in-depth semi-structured phone interviews to fulfill the research goals. Museums, zoos, aquariums, performing arts organizations, heritage foundations, and historical societies were represented. A qualitative approach was adopted, and content analysis on the interview transcripts indicated that cultural institutions implemented digital content to build communities through live and serialized content, partnerships, fundraising, increased transparency, and increased accessibility during temporary closures. Using primarily Instagram and Facebook with their digital content, cultural institutions increased social media engagement during this time. Although there was no consensus on best practices in measuring social media engagement, many institutions highlighted tracking active engagement such as likes, comments, and shares. As a result of the success of the digital content, cultural institutions planned continued digital content campaigns such as videos, blogs, partnerships, and paid educational content in times of normal operations.
\end{abstract}

Keywords: COVID-19; social media; social media engagement; cultural institutions; COVID-19 temporary closures; interviews; content analysis; museums; zoos; aquariums; performing arts organizations

\section{Introduction}

The outbreak of the COVID-19 pandemic transformed the way cultural institutions presented their content to visitors. Cultural institutions such as museums, zoos, aquariums, botanical gardens, performing arts organizations, galleries, and libraries (Carr 1990; Strom 2002) typically rely on communicating their content via in-person experiences. However, as a result of temporary closures enacted internationally during the COVID-19 pandemic, cultural institutions could no longer engage guests in person. They turned to introducing new digital content or further promoting pre-existing digital content to connect with audiences. Although each institution varied, many took advantage of social media to support their digital content during the pandemic. This transformed digital content into their central message and social media into their primary communication medium. Social media allowed institutions to not only communicate their digital content with a wider audience but also receive measurable and significant feedback from this audience (Iwasaki 2017). This feedback took the form of social media engagement (Iwasaki 2017).

Prior research has put considerable efforts in investigating social media engagement in various contexts. The Pew Research Center conducted surveys with American art 
organizations, and the results indicated that $78 \%$ of the organizations say that the internet and digital technologies are very important for increasing audience engagement, and $92 \%$ agree that technology and social media have made art a participatory experience (Adamovic 2013). Russo et al. (2009) reasoned that social media has transformed learning from art museums from a unidirectional experience to one of engagement and participation. This engagement is valued because it results in increased investment from audiences (Muñoz-Expósito et al. 2017). This increased participation and investment make measuring social media engagement a worthwhile venture for cultural institutions. However, due to the dramatic impacts of social distancing on global consumption behaviors (e.g., limited mobility and contacts with service providers) during COVID-19 closures, it is valuable to investigate the changing impacts of social media engagement and strategies cultural institutions would adopt during the COVID-19 temporary closures. Thus, the research will fill a gap in the literature regarding best practices in the types of digital content and social media engagement metrics for cultural institutions during COVID-19 temporary closures. The current study will provide best practices in measuring social media engagement for cultural institutions when it is essentially the only way to measure audience engagement and has a low chance of being influenced by in-person experiences. Specifically, the aim of the study is twofold. First, the research aims to investigate the types of digital content implemented by cultural institutions during COVID-19 temporary closures. It also aims to investigate the impact of the types of digital content on the institutions' social media engagement. Second, the research specifically aims to draw conclusions about the popularity and effectiveness of the different types of digital content used by cultural institutions during this time. Moreover, it seeks to conclude best practices in how cultural institutions measured changes in social media engagement during this period of temporary closures.

The three research questions in this research are as follows:

1. What types of digital content did cultural institutions implement during COVID-19 temporary closures?

2. How was cultural institutions' social media engagement affected by the types of digital content implemented during COVID-19 temporary closures?

3. What digital content did cultural institutions plan to continue implementing after COVID-19 temporary closures?

The research will add to the existing literature by establishing a theoretical relationship between digital content and social media engagement for cultural institutions. Further, the current research will identify specific types of cultural institutions' digital content during temporary closures, changes in social media engagement, and plans for continued digital content campaigns, which were not addressed in a study about COVID-19 temporary closures by the American Alliance of Museums (2020).

From a practical perspective, the findings from the research can indicate best practices in the types of digital content and measures of social media engagement to be used by cultural institutions during temporary closures and normal operations. The impact of this adoption is twofold. First, cultural institutions can continue to engage audiences by leveraging various types of digital content during temporary closures. Second, optimal digital engagement approaches may be identified in the current study to provide valuable suggestions for cultural institutions or even other related service organizations which intend to better engage their customers during temporary closures and normal operations.

This paper will follow the following structure. First, the literature relevant to cultural institutions, types of digital content, and social media engagement will be critically evaluated. Second, the methodology of the current research will be provided, followed by a thematic analysis of the qualitative data collected in this study. Last, the paper will present results, conclusions, implications, and suggestions for further research and practices to be implemented by cultural institutions. 


\section{Literature Review}

\subsection{The Role of Digital Content in Cultural Institutions}

Digital content is defined as bit-based objects distributed through electronic channels and can also be referred to as information products and goods (Koiso-Kanttila 2004). Simply put, digital content is content that is created and uploaded to a website, such as web pages, videos, podcasts, and user-generated content (Holliman and Rowley 2014). It also includes blog posts, white papers, e-books, podcasts, and more (Bogle 2020). It is what audiences expect to experience when visiting a digital platform (Halvorson and Rach 2012). Some take the perspective that the term "digital content" is too technical (Lister 2010). "New media" is an alternative name for digital content that emphasizes digital media that is interactive and involves computing. It can easily be processed, stored, and accessed (Southeastern University 2016). According to Southeastern University (2016), the five types of new media are blogs, virtual reality, social media, online newspapers, and digital games. New media can also refer to social networking, social bookmarking, wikis, P2P file sharing, video clips, and virtual worlds (Friedman and Friedman 2008). Cultural institutions use content that is defined as both "digital content" and "new media."

Digital content is considered to have no intrinsic value. Its value can only be determined by its context, audience, and the time during which it is used (Rowley 2008). This concept is particularly relevant to cultural institutions during COVID-19 temporary closures. Although digital content has had a role in cultural institutions for decades, it can be argued that it became much more valuable in the time and context of the COVID-19 pandemic.

Cultural institutions, museums in particular, have been providing digital content since approximately 1995 (Keene 1996). Museums that incorporated digital content early valued the opportunity to build an online community and invest in interactive programming (Allen-Greil and MacArthur 2010). The Museum Computer Network categorizes the most popular digital content created by museums under the following areas: portals, virtual tours, online exhibits, e-learning, online collections, and digital archives and libraries (Byrd-McDevitt 2020). According to a 2013 survey by the Pew Research Center, 81\% of arts organizations believe that the internet and digital technologies are essential for promoting the arts (Thomson et al. 2013).

The 2018 Themed Entertainment Association report projected that an upcoming trend in museums is customizing experiences to individuals through technology and digital media (Themed Entertainment Association and AECOM 2019). This projection is consistent with Gartner's identification of the top ten technology trends for 2020, which include virtual reality, augmented reality, and mixed reality (Gartner 2019).

However, the introduction of digital content from museums has challenged museums' traditional role of presenting authentic artifacts rather than copies or digital versions. According to Kalay et al. (2008), "[U]nlike traditional means of dissemination, digital media presents viewers with the unique problems of authenticity, interpretability, guidance and contextuality-or rather, the lack thereof" (p. 6).

Diverging from this challenge is a new opportunity that digital content brings. Digital content within cultural institutions offers the opportunity to provide visitors with more accessibility to culture. Digital content allows museums to reach new audiences, specifically, those who traditionally "lacked an access point to the museum and its collection" (Adamovic 2013, p. 18). Considering that education and service to the visitors are paramount to cultural institutions, the importance of cultural institutions providing digital content when possible cannot be ignored.

In most Western European countries, the creation and disbursement of culture are considered to be a public responsibility. Just as valued is the process of making it accessible to visitors. According to Hylland (2017), around the same time that museums began providing digital content in 1995, the democratic potential of digital content was acknowledged by Norway in 1996. Research from Hylland (2017) explored how Norway views information technology as a potential method to make museum content more ac- 
cessible to the public. A report from the Auditor General of Norway asserted that one of the primary goals for digital cultural heritage is providing access (Hylland 2017). This large-scale acknowledgment of the significance of using digital content to provide access to cultural institutions indicates that not only should this content have a considerable impact on audience engagement but there should also be further discussion about making it the standard for cultural institutions beyond times of temporary closures.

\subsection{Social Media Engagement}

Social media is a term that is difficult to define. The term first appeared in the early 1990s to indicate web-based communication tools that allow users to interact online (Treem et al. 2016). Asur and Huberman (2010) defined it as a form of online discourse where users create, share, bookmark, and network. Treem et al. (2016) defined it as online offerings such as blogs, social networking sites, and microblogging that have emerged since the 1990s. Beer and Burrows (2007) referred to social media as establishing web-based applications that allow users to write and contribute content, also known as Web 2.0. These different approaches all emphasize the role of interactivity and engagement, which are paramount to cultural institutions.

According to Muñoz-Expósito et al. (2017), social media engagement refers to audience involvement in the production and performance of the service. It is a bidirectional interaction between the creator and users and is beneficial for both parties (Muñoz-Expósito et al. 2017). Tiago and Veríssimo (2014) argued that entities can improve their digital engagement by focusing on these relationship-based interactions. These interactions include improving dialogue, communication, and customer brand awareness through consistent feedback and information gathering (Tiago and Veríssimo 2014). Organizations have opted to measure social media engagement to determine the effectiveness of their digital and social media content. There are many methods used to measure social media engagement.

First, the types of social media engagement must be explored. At the most basic level, social media engagement is defined as impressions, likes, and comments (Lee et al. 2018). More expansively, likes, dislikes, shares, visits, views, clicks, tags, mentions, hovers, checkins, pins, embedding, endorsements, uploads, and downloads as social media actions can be used to measure social media engagement (Perreault and Mosconi 2018). Paine (2011) divided social media engagement into a series of phases. It begins with clicking and liking, elevates to commenting, following, retweeting, and hashtagging, and ends with advocacy. Cultural institutions thrive on support from their audience; therefore, this suggests that social media engagement can be a useful measure of the overall success of cultural institutions (American Alliance of Museums 2017).

These forms of social media engagement can be measured through a variety of proposed methods. At its most basic, Lee et al. (2018) proposed that engagement on Facebook pages can be measured by the number of comments, likes, and impressions generated. According to Agostino and Arnaboldi (2016), levels of public engagement with social media content can also be separated into two levels-public communication and public participation.

Public communication measures popularity, and its metric for Facebook is

$$
\text { Public Communication }=\frac{\frac{\text { Total \# of Likes }}{\text { Total \# of Posts }}}{\# \text { of Fans }} \times 1000
$$

Public participation measures commitment, and its metric for Facebook is

$$
\text { Public Participation }=\frac{\frac{\text { Total \# of Comments }}{\text { Total \# of Posts }}}{\text { \# of Fans }} \times 1000
$$

For social video engagement, Barry and Graça (2018) suggested measuring engagement with the ratio of the number of comments relative to the number of views. This 
accounts for differences in the average number of total comments that could vary based on certain videos having a high number of views.

For Twitter engagement, Muñoz-Expósito et al. (2017) outlined the most effective measurements. They suggested that effective metrics must consider user interaction in relation to the total number of users exposed to and reached by the same content. To fully explore their metric, which can be applicable to other social media platforms, several terms must first be defined. According to Muñoz-Expósito et al. (2017), interactions refer to retweets, shares via email, replies, likes, detail expands, embedded media clicks, hashtag clicks, follows, user profile clicks, link clicks, permalink clicks, app install attempts, app opens, and leads submitted. Impressions refer to the number of times a Twitter user is exposed to a tweet on a timeline or through search results, regardless of whether the user chooses to click it. Reach is defined as the size of the single audience for a set of tweets. Bringing all of these individual metrics together, Muñoz-Expósito et al. (2017) proposed the following formula to most accurately measure engagement on Twitter:

$$
\text { Engagement on Twitter }=\frac{\frac{\frac{\text { Interactions }}{\text { \# of Tivets }}}{\text { Average Impressions }}}{\text { Average Reach }} \times 100
$$

This ratio indicates the quantity of interactions an organization receives in proportion to the times that the content has been shown and the number of people it has reached (Muñoz-Expósito et al. 2017). Although there are a wide variety of methods to measure social media engagement, the importance of measuring it cannot be understated. In times of temporary closures, it may be one of the only metrics that organizations can use to measure audience engagement.

\section{Methodology}

\subsection{Data Collection}

Qualitative research was the chosen research method for the study to provide rich, dynamic data and flexibility. Given the exploratory nature of the study and the complex of the research problems, a qualitative approach enables the researchers to explore, in depth, the research questions: 1 . What types of digital content did cultural institutions implement during COVID-19 temporary closures? 2. How was cultural institutions' social media engagement affected by the types of digital content implemented during COVID-19 temporary closures? 3. What digital content did cultural institutions plan to continue implementing after COVID-19 temporary closures? The researchers created a semi-structured phone interview protocol to collect data. Participants were recruited by the researchers selecting cultural institutions that received media attention for the digital content they implemented during COVID-19 temporary closures. During the pre-data collection period, the researchers prepared a list of contact information of cultural institutions that adopted social media strategies during COVID-19 temporary closures. Then, the researchers emailed the cultural institutions to ask their interest in participation. After receiving the recruitment email with details of the study, interested cultural institutions consented to a 30-min phone interview to discuss their digital content and social media engagement during COVID-19 temporary closures. The interviews were guided by a list of prepared questions and interviewees were free to skip or further elaborate on any questions when necessary. To limit response bias, all institutions were informed that their identity would remain confidential, leading questions were avoided, no incentives were offered for responding a certain way, and no incentives were offered for participation. Interviews took place between July and September 2020. The researchers reached data saturation at 66 interviews (Fusch and Ness 2015). Although interviews were scheduled for 30 min, each one lasted between approximately 10 and $30 \mathrm{~min}$, depending on the scope of each institution's digital content and social media use. 


\subsection{Data Analysis}

All interviews were recorded with the participants' consent and transcribed for data analysis. Transcriptions were inputted into MAXQDA Analytics Pro 2020 Demo software to assist with thematic analysis (Guest et al. 2012). Using open coding, common themes were identified and expanded throughout a careful reading of the 66 transcriptions. A codebook was created using the themes found during open coding. Using axial coding and selective coding, these themes were then consolidated, and the codebook was finalized. The primary researcher coded the transcripts and achieved inter-rater reliability by having a second individual code a random sample (33 transcripts-50\%) of the interviews. The inter-rater similarity was over $85 \%$, ensuring there was sufficient inter-rater reliability (Landis and Koch 1977).

\section{Results}

Several themes as illustrated below were generated from the data analysis of the 66 interview transcripts. One overarching framework (see Figure 1) is proposed based on the themes to pinpoint the critical stages of virtually engaging visitors of cultural institutions through social media.
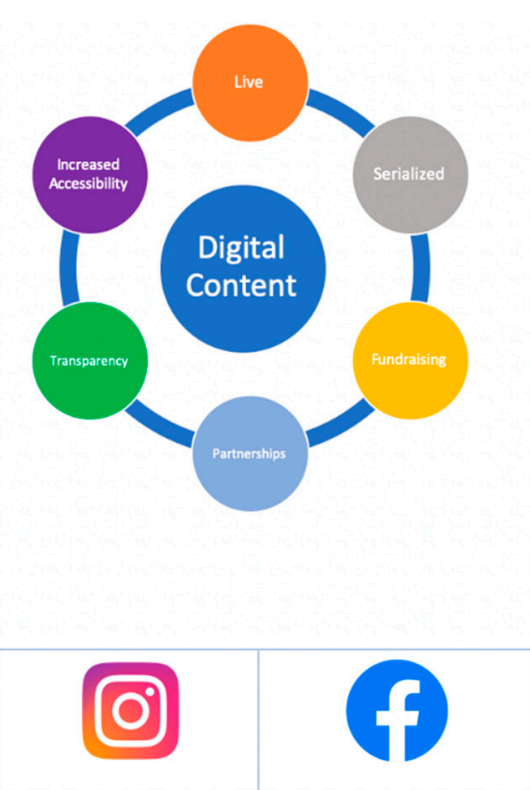

Most Engaging Social Media Platforms

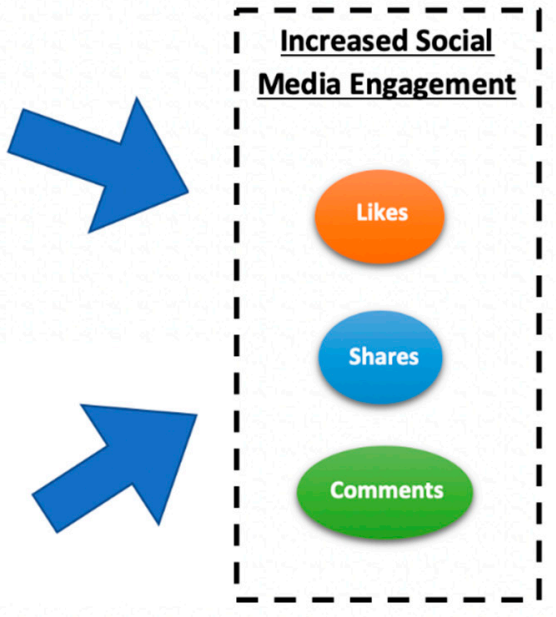

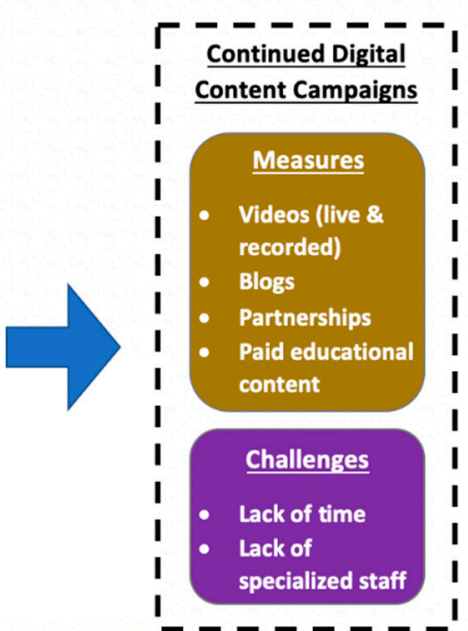

(1)

Figure 1. Factors influencing continued digital content campaigns after COVID-19 temporary closures.

\subsection{Live Digital Content}

The first theme to emerge from the research was the use of live digital content during COVID-19 temporary closures. Thirteen out of sixty-six participants reported implementing live digital content immediately or soon after temporary closures were enacted. Of these institutions, 58 reported using Facebook Live regularly. Forty-four institutions also reported using Zoom for live content, alone or in addition to Facebook Live. With this live digital content, sixty institutions reported implementing youth education, and fifty-seven hosted events. Although several of these institutions indicated that they had used live digital content prior to temporary closures, none reported using it with as much frequency as they did during closures. Several institutions reported that this live digital content maintained or enhanced the connection between the institution and its audience. Forty specifically reported interacting with viewers live in the comments to enhance engage- 
ment and personal connection. In this scenario, live digital content built communities and facilitated real-time interaction.

\subsubsection{Serialized Digital Content}

Serialized digital content was another theme that emerged from the data. Fifty-nine institutions discussed the implementation of serialized digital content to engage audiences during COVID-19 temporary closures. Of these institutions, thirty-four reported using daily themes such as Throwback Thursday, comedy, health and wellness, and story times. Eighteen institutions reported creating series that occurred weekly or when possible for the institution. Serialized content was presented live, through pre-recorded video, social media posts, and blogs. This provided predictable content for audiences to choose to engage with, much in the way a daily schedule would for an in-person experience.

\subsubsection{Fundraising}

Although, to the researchers' knowledge, no literature works exist regarding cultural institutions' most common methods of fundraising prior to COVID-19, the Smithsonian Institution indicates that in-person events are a primary method (Smithsonian Institution 2001). The absence of these events made digital content a key method of fundraising. Fifty-five out of sixty-six cultural institutions reported using digital content to increase donations to their organization. Forty-two institutions provided personalized videos in return for donations. Both of these institutions were zoos or aquariums and would engage audience members with an animal and message of their choice. One institution raised over USD 10,000 within approximately three months with this method. Two more institutions reported requesting donations through their Facebook pages, and three performing arts organization had donors supporting performances. This suggests that digital content is not only a major avenue for fundraising for cultural institutions during times of temporary closures and times of normal operations but also a novel way to engage audiences.

\subsubsection{Partnerships}

Of the 66 institutions interviewed, 26 indicated that they built community partnerships via digital content during COVID-19 temporary closures. The primary type of partnership was with community partners such as local artists and nonprofit organizations. In the performing arts sector, twelve institutions discussed partnerships they developed with a radio station and a television station. This expanded their reach and allowed them to broadcast performances that otherwise would have had to be experienced in person. Additionally, one institution reported partnering with approximately 20 influencers to promote the work of the institution. Although this may be outside the scope of many cultural institutions, it indicates the ability of cultural institutions to have a major digital and social media presence with strategic partnerships.

\subsubsection{Transparency}

A focus on transparency was another theme identified in the study. Thirty-five cultural institutions reported a greater emphasis on transparency in building connections with audiences through digital content during temporary closures. Benefits of this shift in tone included live content feeling more natural, an increase in dialogue between institutions and audiences, and an increase in social media followers.

\subsubsection{Increased Accessibility}

Increased accessibility was a final major theme of digital content identified by participants during COVID-19 temporary closures. Eleven participants, of their own accord, discussed the increased accessibility to cultural institutions that digital content offered. Of the eleven participants that discussed increased accessibility, nine indicated that digital content increased accessibility to the institution to a wider geographical range. Institutions reported reaching audiences across the state, country, and world that they otherwise would 
not have engaged. Reports included audiences watching Facebook Lives from across different states, taking lessons from Germany, livestreaming from Vietnam, and partaking in summer programs from Japan. Additionally, three of the institutions indicated that they provided free content to audiences who, prior to COVID-19 temporary closures, were unable to visit for financial reasons. Finally, two institutions reported that they continued their digital content after reopening to engage audiences with health concerns without compromising their safety.

\subsection{Social Media Engagement}

Social media was a primary platform for cultural institutions to create and share their new digital content. Almost every cultural institution (64 out of 66) reported higher social media engagement during COVID-19 temporary closures. Institutions proposed different reasons for this increased engagement, but two common themes were the new types of digital content and that audiences spent more time on social media during temporary closures. In regard to new digital content increasing engagement, participants also indicated that certain tones or themed days influenced engagement. Digital content with high social media engagement included comedy, positivity, children's activities, hands-on activities, and popular animals at zoos and aquariums. Interestingly, two out of three of the zoos interviewed reported that the host of the live digital content influenced social media engagement. Hosts that were comfortable speaking to the camera and engaging with audiences performed better than those who were not.

Of these 64 participants, 44 reported that they experienced a steady decrease in this increased engagement as the months of temporary closures continued. Twenty-two reported that their social media engagement, although higher than pre-COVID-19 temporary closures numbers, fluctuated over the months of temporary closures and social distancing. Suggested reasons for this included the loss of novelty, audience fatigue, the gradual reopening of institutions, and changes in content. Only 12 out of 66 participants reported no change in social media engagement after the start of temporary closures. Figure 2 displays the typology of social media engagement within cultural institutions.

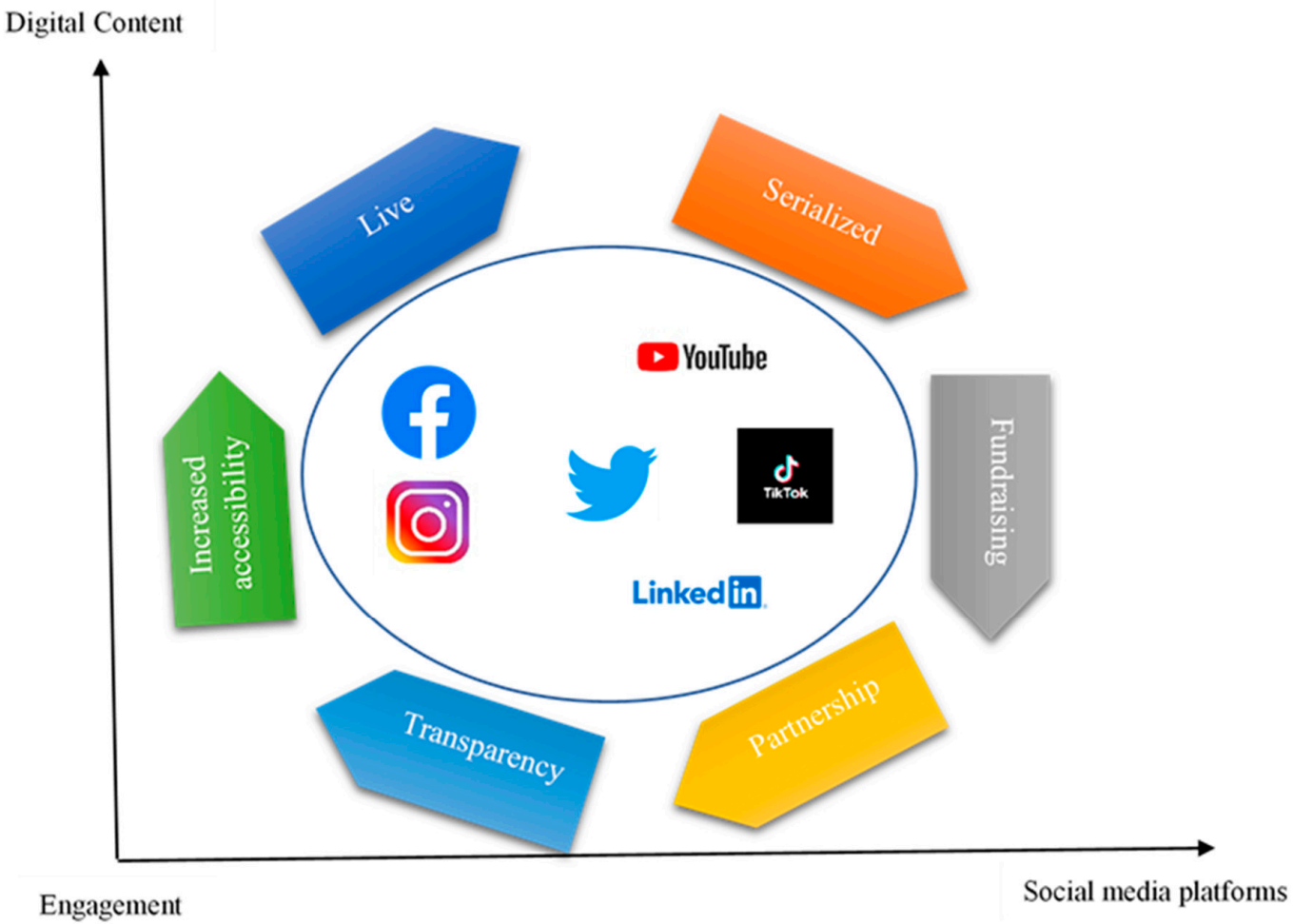

Figure 2. Social media engagement typology within cultural institutions. 


\subsubsection{Facebook and Instagram Became the Most Engaging Platforms}

When discussing social media engagement, 54 out of 66 participants indicated that Facebook and Instagram were the platforms that received the most engagement. Out of these 54, 27 identified Instagram as the platform with the most engagement, 13 identified Facebook, and 4 identified them as receiving equal engagement. Even when either Facebook or Instagram was identified as receiving the most engagement, several participants still indicated that the other platform closely followed. Reported discrepancies were that one of these platforms had more followers but the other had more engagement, the platforms were used for different purposes, or the platforms had different audiences that used the platforms differently. Therefore, even if either Facebook or Instagram received more engagement than the other, both were kept as priorities for most institutions. In regard to other social media platforms, out of all the participants, eleven reported using TikTok as a major platform, sixteen reported tracking Twitter engagement, and twenty reported tracking LinkedIn engagement.

\subsubsection{Measures of Social Media Engagement}

Of the 66 institutions, 33 discussed how they measured social media engagement. Although there was no consensus among participants about the best way to measure social media engagement, some common themes did emerge. Although thirteen participants used the term engagement to define how they measured engagement, several participants specified the metrics they tracked. The most common metrics in descending order were likes, shares, comments, reach, and followers. Thirty participants reported using the engagement rate as a primary method of measuring social media engagement. Twenty indicated that they measured social media engagement success by their conversion rate to website views and ticket sales. Although no clear consensus was found, it is evident that passive metrics such as followers, reach, and impressions were not valued as highly as active audience engagement. In fact, eleven institutions indicated that they were planning to create a custom value system to assign different weights to different types of engagements, with engagements such as comments being given more weight than likes.

\subsection{The Continued Implementation of Digital Content}

Fifty out of sixty-six participants discussed their plans to continue with their digital content beyond COVID-19 temporary closures. Forty institutions planned to continue implementing their digital content in some capacity. Digital content they planned to continue included lessons, personalized videos, blogs, live videos, and pre-recorded videos. All 40 suggested that certain content would be scaled back as in-person offerings began again. However, 17 out of these 40 institutions reported clear plans for growth in digital programs they found success in. Notably, fourteen participants indicated that they planned to continue or expand partnerships that were built digitally during COVID-19 temporary closures. One museum in particular indicated a strong interest in building partnerships with community organizations and members. Other plans for growth included creating paid educational content, transitioning from Facebook Live to a different livestream platform, and using new social media platforms. Two institutions not only planned to continue implementing video content but also planned to improve its quality. Plans for better equipment and studio space were discussed to achieve this goal.

Several institutions indicated that they had intended to increase their digital content and social media presence prior to COVID-19 temporary closures but did not have the opportunity to do so. Several institutions also indicated that temporary closures highlighted the role and importance of digital content for cultural institutions. Given this, it is evident that COVID-19 temporary closures were the catalyst to build and maintain increased digital content and social media engagement. 


\subsection{Challenges}

Thirty out of sixty-six institutions reported that a lack of time was a major challenge in determining the digital content they could continue implementing after COVID-19 temporary closures. Twenty of these thirty institutions were zoos that indicated that animal care staff would not have the time to engage with audiences in person and virtually throughout the day. Given the unpredictable nature of animals, this is a challenge that not only involves the employees' time but also the comfort of the animals. A performing arts organization stated that performers would also no longer have the time to engage at the same capacity during the performance season.

Another related challenge that was mentioned by ten participants was layoffs, which resulted in a lack of specialized staff to create digital content at the same capacity once temporary closures ended. Although other participants did not explicitly state a lack of time and specialized staff as a factor, many placed an emphasis on reducing certain digital content when the focus shifted back to in-person content to meet the demand in normal operations. Notably, two institutions indicated that they were pressured to continue the digital content they implemented because they set a precedent and created audience expectations during temporary closures. One institution stated, "We opened the virtual door and it's going to be hard to close it." This indicates that institutions may have been pressured to meet renewed audience expectations, even when faced with challenges such as staff and time constraints.

All relevant supporting quotes for the proposed themes are listed in Table 1 below.

Table 1. Supporting quotes for the identified themes.

\begin{tabular}{|c|c|c|}
\hline Themes & Properties & Supporting Interview Quotes \\
\hline $\begin{array}{l}\text { Live digital } \\
\text { content }\end{array}$ & $\begin{array}{l}\text { Facebook Live } \\
\text { Instagram Live } \\
\text { Livestream } \\
\text { Events } \\
\text { Education } \\
\text { Comments }\end{array}$ & $\begin{array}{l}\text { "We decided to do some Facebook Live videos as well as just regular } \\
\text { video content." (Performing arts organization A, Southeast) } \\
\text { "We did } 60 \text { days of Facebook Live." (Aquarium A, Southeast) }\end{array}$ \\
\hline $\begin{array}{l}\text { Serialized } \\
\text { digital content }\end{array}$ & $\begin{array}{l}\text { Themed days } \\
\text { Themed weeks } \\
\text { Blogs }\end{array}$ & $\begin{array}{l}\text { "So each day of the week represented something different." (Museum } \\
\text { D, Southwest) } \\
\text { "We actually had a health and wellness series and a weekly } \\
\text { mindfulness series." (Museum A, Southeast) }\end{array}$ \\
\hline Fundraising & $\begin{array}{l}\text { Donations } \\
\text { Paid content }\end{array}$ & $\begin{array}{l}\text { "Just trying to engage and thanking people for donating because we } \\
\text { added a donate button to every single Facebook Liv.e" (Zoo A, } \\
\text { Southeast) } \\
\text { "They can make a donation to the aquarium and for that donation, we } \\
\text { would send a video around } 30 \text { s long with any type of special } \\
\text { instructions that they wanted." (Aquarium A, Southeast) }\end{array}$ \\
\hline Partnerships & $\begin{array}{l}\text { Influencers } \\
\text { Community partners } \\
\text { Radio } \\
\text { TV }\end{array}$ & $\begin{array}{l}\text { "We've collaborated with other organizations for Facebook Live talks." } \\
\text { (Museum C, Northeast) } \\
\text { "We work with local artists in the community and they just kind of } \\
\text { took us, took our audience on a tour of their studio, and those were } \\
\text { doing really well." (Museum B, Southeast) }\end{array}$ \\
\hline Accessibility & $\begin{array}{l}\text { Geographical } \\
\text { Financial } \\
\text { Health }\end{array}$ & $\begin{array}{l}\text { "It's a way to reach schools that aren't in-state so we can reach a } \\
\text { larger audience." (Zoo B, Southwest) } \\
\text { "They're not gonna be able to come for a while or they live out of state, } \\
\text { but they want to support us. And so the virtual is a way to engage } \\
\text { those people differently." (Museum E, Southwest) }\end{array}$ \\
\hline Transparency & $\begin{array}{l}\text { Transparency } \\
\text { Community building } \\
\text { Conversation }\end{array}$ & $\begin{array}{l}\text { "Kind of moving towards showing more constant back and forth and } \\
\text { transparency." (Museum C, Northeast) } \\
\text { "So everyone is, you know, transparent and clear with everyone just } \\
\text { so that we can keep that really strong connection with everyone that } \\
\text { we have." (Performing arts organization B, Southeast) }\end{array}$ \\
\hline
\end{tabular}


Table 1. Cont.

\begin{tabular}{|c|c|c|}
\hline Themes & Properties & Supporting Interview Quotes \\
\hline $\begin{array}{l}\text { Changes in } \\
\text { engagement }\end{array}$ & $\begin{array}{l}\text { Engagement changing } \\
\text { over the course of } \\
\text { COVID-19 }\end{array}$ & $\begin{array}{l}\text { "We've actually seen an increase. So we're almost up to 85,000 } \\
\text { followers on Instagram and over 150,000 on Facebook, and on Twitter } \\
\text { we are almost at 24,000." (Zoo B, Southwest) } \\
\text { "The organic content went further than it ever had." (Museum A, } \\
\text { Southeast) }\end{array}$ \\
\hline $\begin{array}{l}\text { Most engaging } \\
\text { platforms }\end{array}$ & $\begin{array}{l}\text { Facebook } \\
\text { Instagram } \\
\text { Twitter } \\
\text { TikTok } \\
\text { LinkedIn } \\
\text { YouTube }\end{array}$ & $\begin{array}{l}\text { "Facebook for sure, followed by Instagram." (Zoo C, Southwest) } \\
\text { "100\% Instagram. That's where our audience is most active and it's } \\
\text { the platform that's growing the most for us." (Museum B, } \\
\text { Southeast) }\end{array}$ \\
\hline $\begin{array}{l}\text { Measures of } \\
\text { engagement }\end{array}$ & $\begin{array}{l}\text { Followers, likes, } \\
\text { comments, views, } \\
\text { reach, impressions, } \\
\text { shares engagement rate, } \\
\text { conversion rate }\end{array}$ & $\begin{array}{l}\text { "We usually go off of video views, how many followers we're up that } \\
\text { week and then engagement." (Zoo B, Southwest) } \\
\text { "We pretty go by the traditional definition of likes comments, shares } \\
\text { and clicks." (Zoo C, Southwest) }\end{array}$ \\
\hline $\begin{array}{l}\text { Future of } \\
\text { digital content }\end{array}$ & $\begin{array}{l}\text { Reducing digital } \\
\text { content } \\
\text { Increasing digital } \\
\text { content }\end{array}$ & $\begin{array}{l}\text { "We're anticipating living both in person and the digital way maybe } \\
\text { forever, honestly." (Museum D, Southwest) } \\
\text { "And then our education department is also looking at virtual } \\
\text { opportunities that will be paid." (Museum E, Southeast) }\end{array}$ \\
\hline Challenges & $\begin{array}{l}\text { Time } \\
\text { Resources } \\
\text { Audience expectations }\end{array}$ & $\begin{array}{l}\text { "We } 100 \% \text { are keeping with producing this much content only } \\
\text { because we kind of have to." (Museum A, Southeast) } \\
\text { "And musicians are definitely going to get a lot busier." (Performing } \\
\text { arts organization B) }\end{array}$ \\
\hline
\end{tabular}

\section{Conclusions}

Research into cultural institutions' digital content and social media engagement has gained traction as cultural institutions adapt to a changing society. The existing literature identified the role and impact of cultural institutions' digital content, as well as common categories of their social media content (Allen-Greil and MacArthur 2010; Iwasaki 2017; Thomson et al. 2013). The current research adds to this literature by exploring cultural institutions' digital content and its effects on social media engagement specifically during COVID-19 temporary closures. This not only provides insight into digital content and social media engagement in times of COVID-19 temporary closures but also explores implications of their roles in times following them.

Cultural institutions' common use of live digital content and digital partnerships during COVID-19 temporary closures highlights what cultural institutions valued most during this time. The commonly reported focus on live educational programming, events, replying to comments, and transparency indicates that direct engagement with visitors and community building were a priority for institutions. Digital partnerships also worked to further relationships within the community. One of the most significant findings of this research was the increased accessibility to cultural institutions that digital content provided. Audiences who wanted to visit but were unable to do so due to geographical distance, financial reasons, or health concerns were given an access point they otherwise would not have had. Mercier (2017) found that, in addition to cost, those who do not typically visit museums identify atmosphere as a primary barrier. By meeting non-visitors in the more familiar environment of the digital realm, cultural institutions also became more accessible to those who otherwise may not have had a desire to visit. Institutions in the current research recognized the value of this accessibility in building new communities, and several indicated their desire to continue with digital content primarily for this reason. Therefore, a theoretical connection between the accessibility of digital content and community building for cultural institutions was identified in this study.

The lack of focus on producing virtual exhibits and tours suggests that institutions valued their intangible offerings over their tangible ones and that digital content was not intended to completely replace in-person experiences. Rather, digital content was primarily used to build and maintain connections that are typically facilitated by tangible, in-person 
experiences. This is contrary to research that indicated, prior to COVID-19, only $26 \%$ of museums considered building and sustaining communities the most important content for their social media (Iwasaki 2017). This indicates that in times of temporary closures, there is an increased focus on community-building digital content for cultural institutions compared to in times of normal operations.

Most of the digital content was hosted on or promoted through Facebook and Instagram. Although other platforms such as Twitter, TikTok, and YouTube were mentioned, most institutions identified Facebook and Instagram as their focus because they typically received the most engagement on these two platforms. As a result of the digital content and use of Facebook and Instagram, almost every institution experienced an increase in social media engagement during temporary closures. Although there was no consensus on best practices and metrics for measuring social media engagement, institutions emphasized measuring an increase in active engagement such as likes, comments, and shares over passive metrics such as reach, impressions, and followers. This further supports the researchers' theory that building connections and communities was the primary goal of digital content during COVID-19 temporary closures. Once again, this countered the existing literature that found views and impressions to be the most tracked metrics for museums (Iwasaki 2017). This suggests that COVID-19 temporary closures may have caused a shift in best practices in measuring social media engagement for cultural institutions.

For institutions that may doubt the value of increased social media engagement beyond closures, it should be noted that social media has been found to increase involvement, membership, and donations for nonprofit organizations (Waters et al. 2009). Therefore, the identified digital content in the current study has the power to increase involvement, membership, and financial contributions for cultural institutions during COVID-19 temporary closures and normal operations.

Most cultural institutions indicated a strong desire to continue employing the digital content they implemented during COVID-19 temporary closures to some extent. As shown in Figure 1, community-building digital content in conjunction with the use of Facebook and Instagram resulted in increased social media engagement and therefore led to plans to continue these digital content campaigns beyond times of COVID-19 temporary closures. Although the gradual reopening of cultural institutions and other businesses took the focus away from institutions' digital content, the newly recognized value of building and maintaining digital communities remained. The intention of digital content during COVID19 temporary closures was never to fully replace the in-person experience of visiting an institution; therefore, it follows that a return to normal operations did not negate the need for digital content. No longer only supplemental to in-person experiences, digital content became an entry point for those who once lacked access to institutions. It also became another equally valuable avenue to build a community with traditional visitors. This has the longstanding potential to transform how the public views and engages with cultural institutions, far beyond times of COVID-19 temporary closures.

\section{Implications}

The current research fills a gap in the literature regarding best practices in digital content for cultural institutions. It found that live content, serialized content, fundraising, partnerships, transparency, and increased accessibility were of most importance to cultural institutions and the most effective during COVID-19 temporary closures. The current research also draws a theoretical connection between digital content and accessibility to cultural institutions. Furthermore, it also identifies that active metrics such as likes, shares, and comments are the preferred method of measuring social media engagement for cultural institutions. Finally, the research identified that the use of community-building digital content and Instagram and Facebook positively influenced social media engagement for cultural institutions during COVID-19 temporary closures.

There are several practical implications of the current research. Cultural institutions can continue implementing the identified digital content to effectively increase social media 
engagement and provide more accessibility during COVID-19 temporary closures. They can also continue measuring social media engagement by likes, shares, and comments as a best practice. Furthermore, cultural institutions can continue these identified actions in times of normal operations for sustained success, as can other service-oriented businesses.

To overcome the identified challenge of a lack of time in continued digital content campaigns, cultural institutions can consider providing a financial incentive for employees who are featured in the digital content. Rather than including digital content as part of the employees' regular duties, institutions can reward participation with the financial benefits reaped from the success of the digital content campaigns.

Additionally, given the indication that the initial increased social media engagement may slowly decrease over the course of temporary closures, cultural institutions can minimize this by preventing audience fatigue. Some recommendations are to provide varied content, compelling hosts for live content, and personalized experiences.

\section{Limitations and Future Research}

Though many rich findings are presented in the current study, there are several limitations which require future research efforts. First, the current study addressed the types of digital content implemented and their effects on social media engagement during COVID-19 temporary closures; however, it did not isolate a direct cause-effect relationship between digital content and social media engagement for cultural institutions. Second, this study did not quantify the changes in digital content and social media engagement. Given that this study took place during the first six months of COVID-19 temporary closures and social distancing measures, the interviews were conducted during different phases of COVID-19 social distancing measures. Institutions were permitted to incrementally open and increase capacity according to state and local guidelines, which resulted in interviews occurring prior to and after the reopening of cultural institutions (The White House 2020). Further, this study only recruited cultural institutions who agreed to participate; therefore, the data source may lack representativeness of all the US cultural institutions. Researchers in future research projects are advised to adopt more scientific sampling approaches to improve the generalizability of the study findings.

Future research should aim to quantify the changes in digital content and social media engagement in a time when all institutions are in the same phase of operations. Future research should also aim to identify changes in cultural institutions' digital content and social media engagement between COVID-19 temporary closures and after a return to normal operations. This will indicate the long-term effects and success of the digital content implemented.

Author Contributions: Conceptualization: B.R., T.Z., N.H.; Methodology: B.R., T.Z.; Software: B.R.; Analysis: B.R.; Writing—original draft preparation: B.R.; Writing—review and editing: T.Z., N.H.; Supervision: T.Z., N.H. All authors have read and agreed to the published version of the manuscript.

Funding: This research received no external funding.

Institutional Review Board Statement: Not applicable.

Informed Consent Statement: Not applicable.

Data Availability Statement: Data is unavailable because of privacy issues.

Conflicts of Interest: The authors declare no conflict of interest.

\section{References}

Adamovic, Meghan. 2013. Social Media and Art Museums: Measuring Success. Master's thesis, University of Oregon, Eugene, OR, USA. Unpublished.

Agostino, Deborah, and Michela Arnaboldi. 2016. A measurement framework for assessing the contribution of social media to public engagement: An empirical analysis on Facebook. Public Management Review 18: 1289-307. [CrossRef]

Allen-Greil, Dana, and Matthew MacArthur. 2010. Small Towns and Big Cities: How Museums Foster Community On-Line. Available online: http:/ / www.archimuse.com/mw2010/papers/allen-greil/allen-greil.html (accessed on 13 May 2020). 
American Alliance of Museums. 2017. Museums Advocacy Day. Available online: https://www.aam-us.org/programs/museumsadvocacy-day/ (accessed on 15 May 2020).

American Alliance of Museums. 2020. National Survey of COVID-19 Impact on United States Museums [PPT]. Arlington: American Alliance of Museums.

Asur, Sitaram, and Bernardo A. Huberman. 2010. Predicting the Future with Social Media. Paper presented at the 2010 IEEE/WIC/ACM International Conference on Web Intelligence and Intelligent Agent Technology, Toronto, ON, Canada, August 31-September 3.

Barry, James M., and Sandra S. Graça. 2018. Humor effectiveness in social video engagement. Journal of Marketing Theory and Practice 26: 158-80. [CrossRef]

Beer, David, and Roger Burrows. 2007. Sociology and, of and in Web 2.0: Some Initial Considerations. Sociological Research Online 12: 67-79. [CrossRef]

Bogle, Susan. 2020. What are the 7 Types of Digital Marketing? Available online: https://www.snhu.edu/about-us/newsroom/2017 /11/types-of-digital-marketing (accessed on 15 May 2020).

Byrd-McDevitt, Logon. 2020. The Ultimate Guide to Virtual Museum Resources. Available online: https://mcn.edu/a-guide-tovirtual-museum-resources/ (accessed on 15 May 2020).

Carr, D. 1990. Qualitative Meaning in Cultural Institutions. Journal of Education for Library and Information Science 31: 97. [CrossRef]

Friedman, Linda Weiser, and Hershey H. Friedman. 2008. The New Media Technologies: Overview and Research Framework. SSRN Electronic Journal. [CrossRef]

Fusch, Patricia I., and Lawrence R. Ness. 2015. Are We There Yet? Data Saturation in Qualitative Research. The Qualitative Report 20: 1408-16.

Gartner. 2019. Gartner Identifies the Top 10 Strategic Technology Trends for 2020. Available online: https://www.gartner.com/ en/newsroom/press-releases /2019-10-21-gartner-identifies-the-top-10-strategic-technology-trends-for-2020 (accessed on 15 May 2020).

Guest, Greg, Kathleen M. MacQueen, and Emily E. Namey. 2012. Applied Thematic Analysis. Los Angeles: Sage.

Halvorson, Kristina, and Melissa Rach. 2012. Content Strategy for the Web. Berkeley: New Riders.

Holliman, Geraint, and Jennifer Rowley. 2014. Business to business digital content marketing: Marketers' perceptions of best practice. Journal of Research in Interactive Marketing 8: 269-93. [CrossRef]

Hylland, Ole Marius. 2017. Even Better than the Real Thing? Digital Copies and Digital Museums in a Digital Cultural Policy. Culture Unbound: Journal of Current Cultural Research 9: 62-84. [CrossRef]

Iwasaki, Shae Toshiko. 2017. Social Media and Museums: Reframing Audience Engagement in the Digital Communication Age. Master's thesis, San Francisco State University, San Francisco, CA, USA. Unpublished.

Kalay, Yehuda, Thomas Kvan, and Janice Affleck. 2008. Introduction. In New Heritage: New Media and Cultural Heritage. London: Routledge, p. 6.

Keene, Suzanne. 1996. Becoming digital. Museum Management and Curatorship 15: 299-313. [CrossRef]

Koiso-Kanttila, Nina. 2004. Digital Content Marketing: A Literature Synthesis. Journal of Marketing Management 20: 45-65. [CrossRef]

Landis, J. Richard, and Gary G. Koch. 1977. An Application of Hierarchical Kappa-type Statistics in the Assessment of Majority Agreement among Multiple Observers. Biometrics 33: 363-74. [CrossRef] [PubMed]

Lee, Dokyun, Kartik Hosanagar, and Harikesh S. Nair. 2018. Advertising Content and Consumer Engagement on Social Media: Evidence from Facebook. Management Science 64: 5105-31. [CrossRef]

Lister, Martin. 2010. New Media: A critical Introduction. London: Routledge.

Mercier, Garrett Kevin. 2017. Differential Concerns: Perceived Benefits and Barriers to Visitation from the Mental Models of Museum Visitors and Non-Visitors. Master's thesis, University of Washington, Washington, DC, USA. Unpublished.

Muñoz-Expósito, Miriam, M. Ángeles Oviedo-García, and Mario Castellanos-Verdugo. 2017. How to measure engagement in Twitter: Advancing a metric. Internet Research 27: 1122-48. [CrossRef]

Paine, Katie Delahaye. 2011. Measure What Matters: Online Tools for Understanding Customers, Social Media, Engagement, and Key Relationships. Hoboken: Wiley.

Perreault, Marie-Catherine, and Elaine Mosconi. 2018. Social Media Engagement: Content Strategy and Metrics Research Opportunities. Paper presented at the 51st Hawaii International Conference on System Sciences, Waikoloa Village, HI, USA, January $2-6$.

Rowley, Jennifer. 2008. Understanding digital content marketing. Journal of Marketing Management 24: 517-40. [CrossRef]

Russo, Angelina, Jerry Watkins, and Susan Groundwater-Smith. 2009. The impact of social media on informal learning in museums. Educational Media International 46: 153-66. [CrossRef]

Smithsonian Institution. 2001. Fundraising at Art Museums.

Southeastern University. 2016. What Is New Media? Available online: https://online.seu.edu/articles/what-is-new-media/ (accessed on 13 May 2020).

Strom, Elizabeth. 2002. Converting Pork into Porcelain. Urban Affairs Review 38: 3-21. [CrossRef]

The White House. 2020. Opening Up America Again. Available online: https:/ / www.whitehouse.gov/openingamerica/ (accessed on 28 October 2020).

Themed Entertainment Association and AECOM. 2019. Theme Index and Museum Index: The Global Attractions Attendance Report. Available online: http:/ / www.teaconnect.org/images/files/TEA_328_381804_190528.pdf (accessed on 15 May 2020). 
Thomson, Kristin, Kristen Purcell, and Lee Rainie. 2013. Arts Organizations and Digital Technologies. Available online: https: //www.pewresearch.org/internet/2013/01/04/arts-organizations-and-digital-technologies/ (accessed on 13 May 2020).

Tiago, Maria Teresa Pinheiro Melo Borges, and José Manuel Cristóvão Veríssimo. 2014. Digital marketing and social media: Why bother? Business Horizons 57: 703-708. [CrossRef]

Treem, Jeffrey W., Stephanie L. Dailey, Casey S. Pierce, and Diana Biffl. 2016. What We Are Talking About When We Talk About Social Media: A Framework for Study. Sociology Compass 10: 768-84. [CrossRef]

Waters, Richard D., Emily Burnett, Anna Lamm, and Jessica Lucas. 2009. Engaging stakeholders through social networking: How nonprofit organizations are using Facebook. Public Relations Review 35: 102-106. [CrossRef] 